\title{
COMPARATIVE STUDIES OF DICTYNA AND MALLOS: V. TOLERANCE AND RESISTANCE TO STARVATION
}

\author{
BY ROBERT R. JACKSON* \\ North Carolina Mental Health Research \\ Anderson Hall, Dorothea Dix Hospital \\ Raleigh, North Carolina 27611
}

\section{INTRODUCTION}

In recent years, there has been an increasing interest in social spiders (recent review: Krafft, 1979); and in particular, efforts have begun to compare the social adaptations that have evolved in spiders with those known for insects (Wilson, 1971).

Kullmann $(1968,1972)$ emphasized cooperation, interattraction, and tolerance as essential characteristics that distinguish social from solitary spiders. Cooperation refers to social spiders working together in some sense, and interattraction concerns the formation of groups due to conspecific spiders attracting each other. Tolerance refers to the non-aggressive, and especially, the non-cannibalistic nature of social spiders.

In a group of closely related web-building spiders from the dictynid genera Mallos and Dictyna, there is considerable interspecific variation in social organization (Jackson, 1978a). Comparative studies of these provide a means by which the particular qualities of sociality occurring in spiders can be assessed.

Earlier studies have been especially concerned with interattraction (Jackson, 1981), cooperation (Jackson, 1979a), and other aspects of the biology of these spiders (e.g., Jackson, 1978b; Witt, et al., 1978). Burgess (1979) considered a particular aspect of tolerance, the vibratory stimuli that elicit predatory behavior and how these differ from the vibrations produced by conspecific spiders. The present study considers some additional questions about tolerance and related comparative aspects of the biology of dictynid spiders.

Most species in these genera are solitary, living one spider per web, except for the common exception of cohabiting male-female pairs

*Present Address: Department of Zoology, University of Canterbury, Christchurch 1, New Zealand

Manuscript received by the editor November 12, 1980. 
(Jackson, 1977). M. trivittatus, D. calcurata, and D. albopilosa are communal, territorial. They live in web complexes divided into defended web units. One or a small group of spiders occupy each unit, separated from other units by interstitial threads. M. gregalis is communal, non-territorial; and hundreds or thousands of individuals occupy single communal webs not divided into defended units (Jackson \& Smith, 1978).

Aggression and cannibalism are pronounced in the solitary and communal, territorial species, but almost never observed in laboratory colonies of $M$. gregalis which were normally provided with insect prey (adult Musca domestica or Drosophila melanogaster) once or twice per week. This raises the question of whether cannibalism would occur if the spiders were nutritionally stressed. In casual observations of small colonies kept without prey for 3-4 weeks, cannibalism was not seen (Jackson, 1979b; P. N. Witt, pers. comm.); but considering the renowned capacities of spiders to resist starvation (Anderson, 1974), it is difficult to assess the nutritional stress to which these spiders were subjected. Consequently these observations were extended by keeping colonies of $M$. gregalis indefinitely without alternative prey in order to see whether the spiders would resort to cannibalism before starving to death.

In these observations, it was noted that adult males died sooner than the adult females and immatures. More casual observations in the laboratory also indicated that adult males of $M$. gregalis were more difficult to keep alive, even if provided with insect prey, and that they differed in this respect from the other species of Mallos and Dictyna. Additional observations were carried out in order to clarify this aspect of the biology of these spiders.

\section{Methods ANd Materials}

The laboratory colony of $M$. gregalis originated from spiders collected by J. W. Burgess (1976) near Guadalajara, Mexico. M. trivittatus were collected in Arizona and D. calcurata near Lake Chapala, Mexico, by the author (Jackson, 1978a).

Two types of transparent, plastic cages were used: small ones constructed from 9-cm-diameter petri dishes; large, from $10 \times 10 \times 6$ $\mathrm{cm}$ boxes. Details of cage design and maintenance are provided elsewhere (Jackson, 1974, 1979b).

The terms "male" and "female" will be used for adults only. 
"Immatures" were always individuals $2 \mathrm{~mm}$ or less in body length. Females of $M$. trivittatus tended to be $7 \mathrm{~mm}$ in body length; males, 5 $\mathrm{mm}$. The adults of the other two species tended to be $4-5 \mathrm{~mm}$ in body length.

Statistical tests are from Sokal and Rohlf(1969). Transformations were carried out with the Mann-Whitney tests that permitted the use of tables for the Student t-statistic.

\section{MAINTENANCE OF MALLOS GREGALIS WITHOUT INSECT PREY}

Eight colonies were set up in large cages. Two males, two females, and two immatures were placed in each. The colonies were provided with Musca for two weeks, then all fly carcasses were removed. Any spider that died during this preliminary period was removed and replaced with another individual of the same sex/age class. Subsequently, the colonies were maintained without insect prey until all spiders were dead.

Each colony was observed for at least 5 min three times per day: morning, early afternoon, and late afternoon or evening. However, periods of observation were generally much longer than this, since the colonies were kept on or near my desk and observed intermittently throughout the day when I was present.

\section{MAINTENANCE WITH INSECT PREY}

For these observations, the spiders were kept individually in small cages for $\mathbf{3 0}$ days and provided either one Musca or five Drosophila once per week. Each spider constructed its own web during the 30day observation period. In addition to the total of 135 males referred to in Table 1 and to the 80 females and immatures of $M$. gregalis referred to in Table 2, 40 females and 40 immatures each of $M$. trivittatus and $D$. calcurata were set up. Twenty of each class were provided Musca; the other 20, Drosophila.

In another 130 cases, females of $M$. gregalis were placed one per cage, then left for one week. One male $M$. gregalis was then placed in each cage and provided Musca (60) or Drosophila (70) as described above. In half of each of these groups, the females were removed before the male was introduced into the web. 


\section{Results AND Discussion}

\section{TOLERANCE}

Well-fed M. gregalis are tolerant (i.e., non-cannibalistic and nonaggressive), and the present study indicates that they remain tolerant to what seems the ultimate extent: when kept without alternative prey, they starve to death rather than resort to cannibalism.

No $M$. gregalis was seen feeding on conspecifics, and none of the dead ones had the appearance of having been eaten. When spiders contacted other living or dead conspecifics, they simply walked away, either immediately or after briefly tapping with their legs.

Although it is tempting to view the absence of cannibalism in $M$. gregalis as altruistic and to entertain familiar hypotheses such as kin selection (e.g., Wilson, 1971), a cautionary remark seems appropriate. Few observations have been made on these spiders in their natural habitats, and how often colonies encounter shortages of insect prey is unknown. However, considerations of this sort seem important in assessing whether, and if so to what extent, tolerance is altruistic, especially since the issue is not something the spiders do but something they fail to do.

\section{SEX AND SPECIES DIFFERENCES IN SURVIVAL}

In the colonies left indefinitely without insect prey, males died sooner than females (Fig. 1; Mann-Whitney U-test, $t=5.599, \mathrm{P}<$ 0.001 ). No males survived beyond 23 days, although females and immatures survived as long as 53 days. There were no evident differences in survival times for females and immatures.

Male spiders may generally be adapted to a lifestyle that emphasizes courtship, mating, and searching for females at the expense of maintenance functions that serve to prolong survival (Ghiselin, 1974; Jackson, 1978c). The earlier deaths of males in colonies maintained without prey would seem to be a reflection of this in M. gregalis. Perhaps males lack the capacity to store nutrients to get them through periods without prey, or possibly they are behaviorally and/or physiologically more active and require greater amounts of nutrients per unit time than females and immatures.

However, the difficulty in keeping males of $M$. gregalis alive seems also to be a reflection of differences in the biology of this and the other two species. When provided in their own webs with insect prey, many males of $M$. gregalis died; but only a few of those of the other 

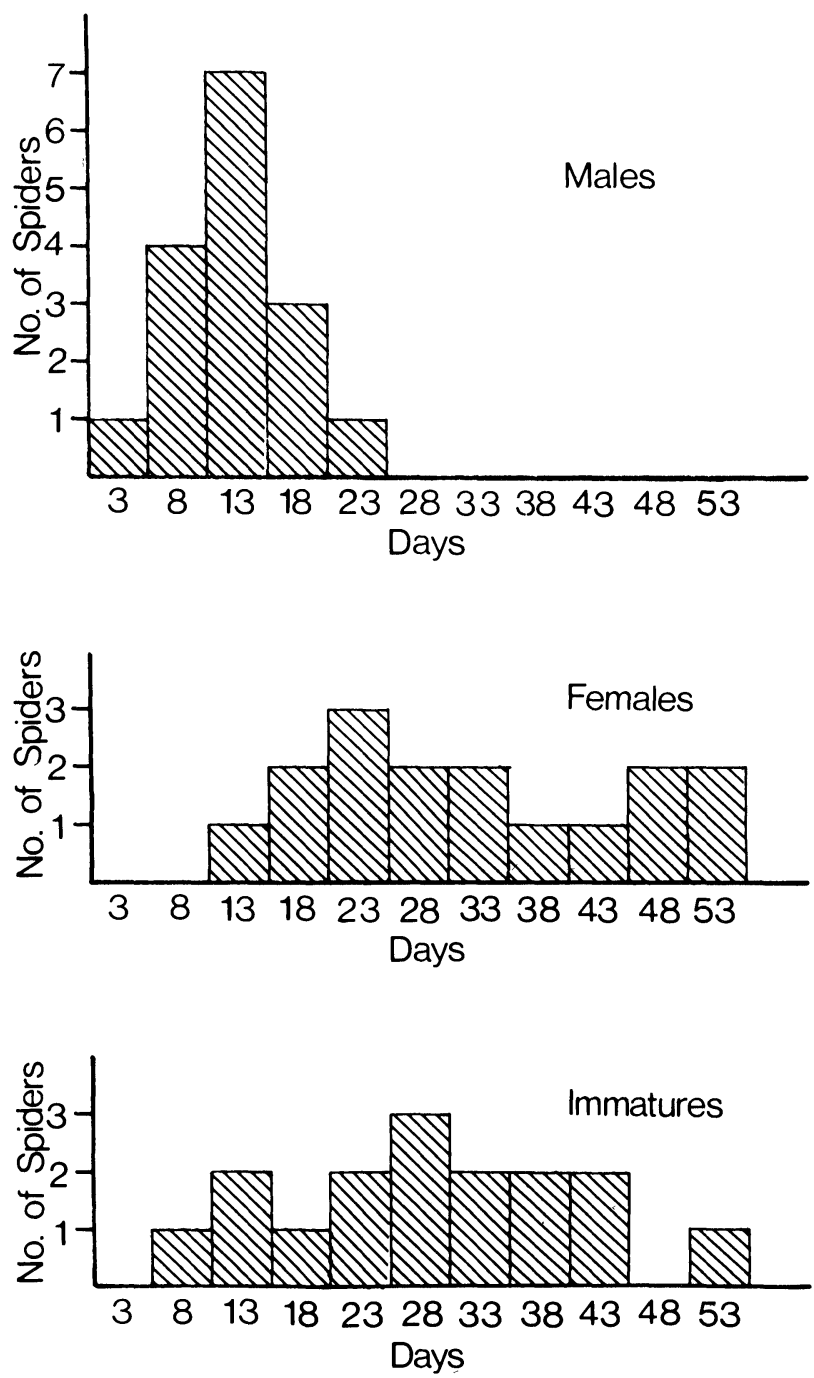

Fig. 1. Frequency distributions for Mallos gregalis showing the numbers of individuals that died after different numbers of days without insect prey. Spiders kept in colonies. See text for details. 3: from the first until the fifth day without insect prey. 8: from the sixth until the tenth day without insect prey, etc. Note: males died sooner than females and immatures. 
species died (Table 1). When maintained with insect prey, survival rates for all sex/age classes of $M$. trivittatus and D. calcurata were high. (No females of either species died during the 30-day period. Only 3 immatures of M. trivittatus and one of D. calcurata died. For the males, see Table 1.)

Table 1. Adult males of three different species maintained for 30 days with either Musca domestica or Drosophila melanogaster provided as prey. G-tests of independence, with Yates Correction, carried out separately for survival rates of those provided with each of the two types of prey: $\mathbf{P}<0.001$.

\begin{tabular}{llcccc}
\hline \multirow{2}{*}{ Prey } & \multicolumn{1}{c}{ Species } & Survived & $\begin{array}{c}\text { Number of Males } \\
\text { Died }\end{array}$ & Total & G \\
\hline \multirow{4}{*}{ Musca } & Mallos gregalis & 12 & 8 & 20 & \\
& Mallos trivittatus & 20 & 0 & 20 & 15.864 \\
& Dictyna calcurata & 19 & 1 & 20 & \\
& & & & & \\
\multirow{4}{*}{ Drosophila } & Mallos gregalis & 21 & 14 & 35 & \multirow{7}{*}{ Mallos trivittatus } \\
& Dictyna calcurata & 19 & 1 & 20 & 20.008 \\
& & 20 & 0 & 20 & \\
\hline
\end{tabular}

Since males of $M$. gregalis lack functional cribella (Jackson, 1979a), their webs are not adhesive and evidently not very effective in prey capture; no males were observed feeding in their own webs. However, males of $M$. trivattatus and $D$. calcurata, which also lack functional cribella (unpub. obs.), were observed feeding in their own webs. Perhaps males of $M$. gregalis rarely move off the large communal webs containing females and immatures. In contrast, while searching for mates, males of $M$. trivittatus and $D$. calcurata may spend considerable time away from webs containing females and immatures; and capabilities of capturing prey without the use of adhesive webs may be adaptations related to this.

Within 30 days, all males died in the colonies kept without insect prey, but more than half survived in their own webs when insects were available. This suggests that males may have fed at times other than when observed, perhaps by scavenging on insects that died in their cages. 
Dependence on conspecifics for survival seems more pronounced for the males of $M$. gregalis than for the females and immatures. Although individuals of $M$. gregalis normally feed and construct their webs in groups, females and immatures have functional cribella; and they can construct and use adhesive webs to capture insects alone. Thus, males of $M$. gregalis died more frequently than females and immatures of this species when in their own webs (Table 2).

Few males of $M$. gregalis died when kept for 30 days with females (Table 3); and often they were observed feeding, alone or with the females, on both Musca and Drosophila. When alone in webs built by females, few of the males provided with Drosophila, but many of those provided with Musca, died. Musca often adhered to the webs; but unlike the Drosophila, they usually struggled violently; and the males were sometimes seen running from them. With females present, males were seen joining the other spiders to feed on Musca whose struggles had begun to subside but not to begin feeding alone on struggling flies. Possibly at least a partial explanation for the differences in survival in Table 3 can be found in this cautious behavior of the males.

Table 2. Adult males, adult females, and immatures of Mallos gregalis maintained for $\mathbf{3 0}$ days with either Musca domestica or Drosophila melanogaster provided as a prey. G-tests of independence, with Yates Correction, carried out separately for survival rates of those provided with each of the two types of prey: $\mathrm{P}<0.001$.

\begin{tabular}{|c|c|c|c|c|c|}
\hline \multirow[b]{2}{*}{ Prey } & \multirow[b]{2}{*}{ Sex/Age Class } & \multicolumn{3}{|c|}{ Number of Spiders } & \multirow[b]{2}{*}{ G } \\
\hline & & Survived & Died & Total & \\
\hline \multirow{3}{*}{ Musca } & Males & 12 & 8 & 20 & \multirow{3}{*}{13.110} \\
\hline & Females & 20 & 0 & 20 & \\
\hline & Immatures & 16 & 4 & 20 & \\
\hline \multirow{3}{*}{ Drosophila } & Males & 21 & 14 & 35 & \multirow{3}{*}{12.226} \\
\hline & Females & 19 & 1 & 20 & \\
\hline & Immatures & 18 & 2 & 20 & \\
\hline
\end{tabular}


Table 3. Adult males of Mallos gregalis maintained for 30 days in different types of webs with either Musca domestica or Drosophila melanogaster provided as prey. Gtests of independence, with Yates Correction, carried out separately for survival rates of those provided with each of the two types of prey: $\mathrm{P}<0.001$.

\begin{tabular}{|c|c|c|c|c|c|}
\hline \multirow[b]{2}{*}{ Prey } & \multirow[b]{2}{*}{ Type of Web } & \multicolumn{3}{|c|}{ Number of Males } & \multirow[b]{2}{*}{ G } \\
\hline & & Survived & Died & Total & \\
\hline \multirow{3}{*}{ Musca } & Built by the Male & 12 & 8 & 20 & \multirow{3}{*}{21.508} \\
\hline & $\begin{array}{c}\text { Built by a Female } \\
\text { Female Absent }\end{array}$ & 11 & 9 & 20 & \\
\hline & $\begin{array}{r}\text { Built by a Female } \\
\text { Female Present }\end{array}$ & 39 & 1 & 40 & \\
\hline \multirow{3}{*}{ Drosophila } & Built by the Male & 21 & 14 & 35 & \multirow{3}{*}{16.380} \\
\hline & $\begin{array}{c}\text { Built by a Female } \\
\text { Female Absent }\end{array}$ & 33 & 2 & 35 & \\
\hline & $\begin{array}{l}\text { Built by aFemale } \\
\text { Female Present }\end{array}$ & 32 & 3 & 35 & \\
\hline
\end{tabular}

\section{SUMMARY}

1. When kept without alternative prey, individuals in colonies of the communal, non-territorial spider Mallos gregalis starved to death rather than resort to cannibalism.

2. Males of $M$. gregalis died sooner than females and immatures when kept without prey.

3. Compared with males of the communal, territorial species $M$. trivittatus and Dictyna calcurata, males of M. gregalis did not survive as long without prey when maintained in their own webs.

4. With prey (Musca and Drosophila) provided, males of $M$. gregalis survived longer when sharing webs with females than when alone.

5. With small prey (Drosophila) provided, males survived longer alone in webs built by females than alone in their own webs.

\section{ACKNOWLEDGEMENTS}

The assistance of Peter N. Witt during all phases of this work is gratefully acknowledged. Yael Lubin provided helpful comments on 
the manuscript. I thank Mary Catharine Vick for assistance with the preparation of the manuscript. Charles Griswold, Steve Jackson, and Vincent Roth assisted in locating spiders in the field. Helpful discussions and assistance in identifying specimens were provided by Willis Gertsch. The assistance of the Southwestern Research Station of the American Museum of Natural History is gratefully acknowledged. This work was supported in part by National Science Foundation Grant BMS 75-09915 to P. N. Witt.

\section{Literature Cited}

Anderson, J. F.

1974. Responses to starvation in the spiders Lycosa lenta Hentz, and Filistata hibernalis (Hentz). Ecology 55: 576-585.

Burgess, J. W.

1976. Social spiders. Sci. Amer. 234: 100-106.

1979. Web-signal processing for tolerance and group predation in the social spider Mallos gregalis Simon. Anim. Behav. 27: 157-164.

GHISELIN, M. T.

1974. The Economy of Nature and the Evolution of Sex. University of California Press: Berkeley.

JACKSON, R. R.

1974. Rearing methods for spiders. J. Arachnol. 2: 53-56.

1977. Web sharing by males and females of dictynid spiders. Bull. Br. Arachnol. Soc. 4: $109-112$.

1978a. Comparative studies of Dictyna and Mallos (Araneae, Dictynidae): I. Social organization and web characteristics. Rev. Arachnol. 1: 133-164.

1978b. Male mating strategies of dictynid spiders with differing types of social organization. Symp. Zool. Soc. Lond. 42: 79-88.

1978c. Life history of Phidippus johnsoni (Araneae, Salticidae). J. Arachnol. 6: 1-29.

1979a. Predatory behavior of the social spider Mallos gregalis: Is it cooperative? Ins. Soc. 26: 300-312.

1979b. Comparative studies of Dictyna and Mallos (Araneae, Dictynidae): II. The relationship between courtship, mating, aggression and cannibalism in species with differing types of social organization. Rev. Arachnol. 2: 103-132.

1981. Comparative studies of Dictyna and Mallos (Araneae: Dictynidae): IV. Silk-mediated interattraction. Ins. Soc. In press.

JACKSON, R. R. \& S. E. SMITH

1978. Aggregations of Mallos and Dictyna: Population characteristics. Psyche 85: $65-80$.

KRAFFT, B.

1979. Organisation et évolution des sociétés d'araignées. J. Psychol. 1: 23-51.

Kullmann, E.

1968. Soziale Phaenomene bei Spinnen. Ins. Soc. 15: 289-298. 
1972. Evolution of social behavior in spiders (Araneae: Eresidae and Theridiidae). Amer. Zool. 12: 419-426.

SOKAL, R. R. \& F. J. RoHLF

1969. Biometry. Freeman: San Francisco.

WILSON, E. O.

1971. The Insect Societies. Belknap Press: Cambridge, Mass.

Witt, P. N., M. B. Scarboro, \& D. B. Peakall

1978. Comparative feeding data in three spider species of different sociality: Araneas diadematus $\mathrm{Cl}$., Mallos trivattatus (Banks), and Mallos gregalis (Simon). Symp. Zool. Soc. Lond. 42: 89-97. 

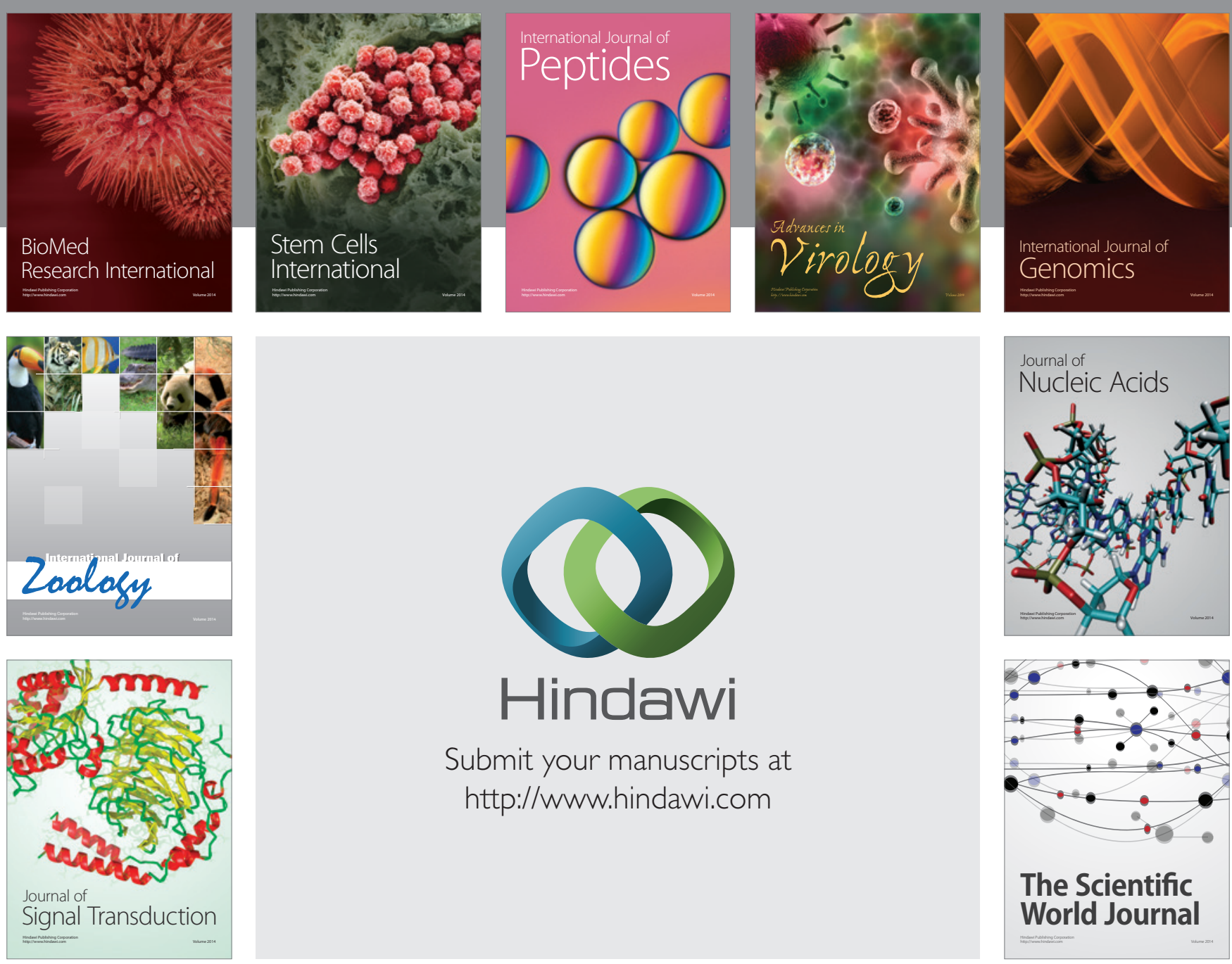

Submit your manuscripts at

http://www.hindawi.com
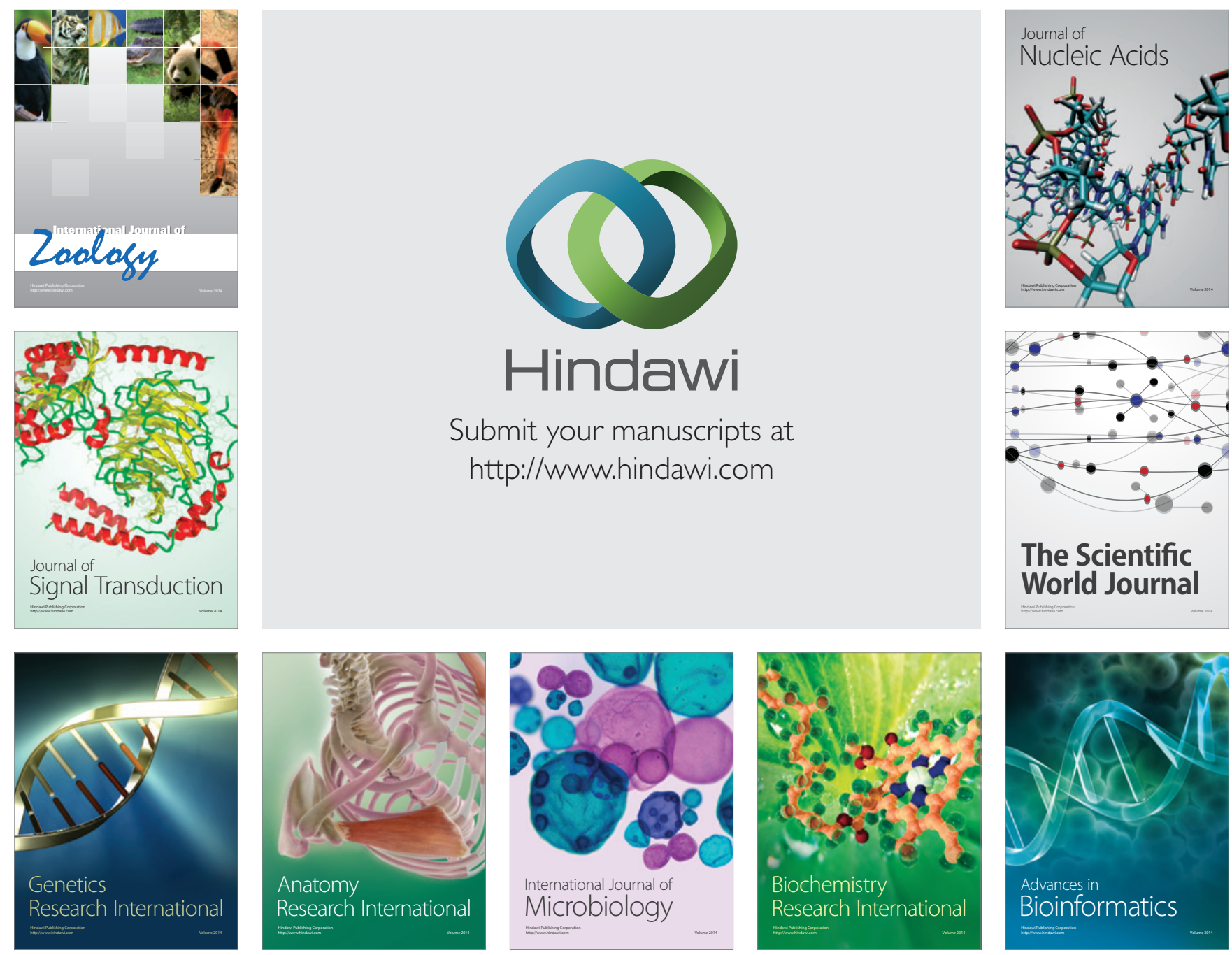

The Scientific World Journal
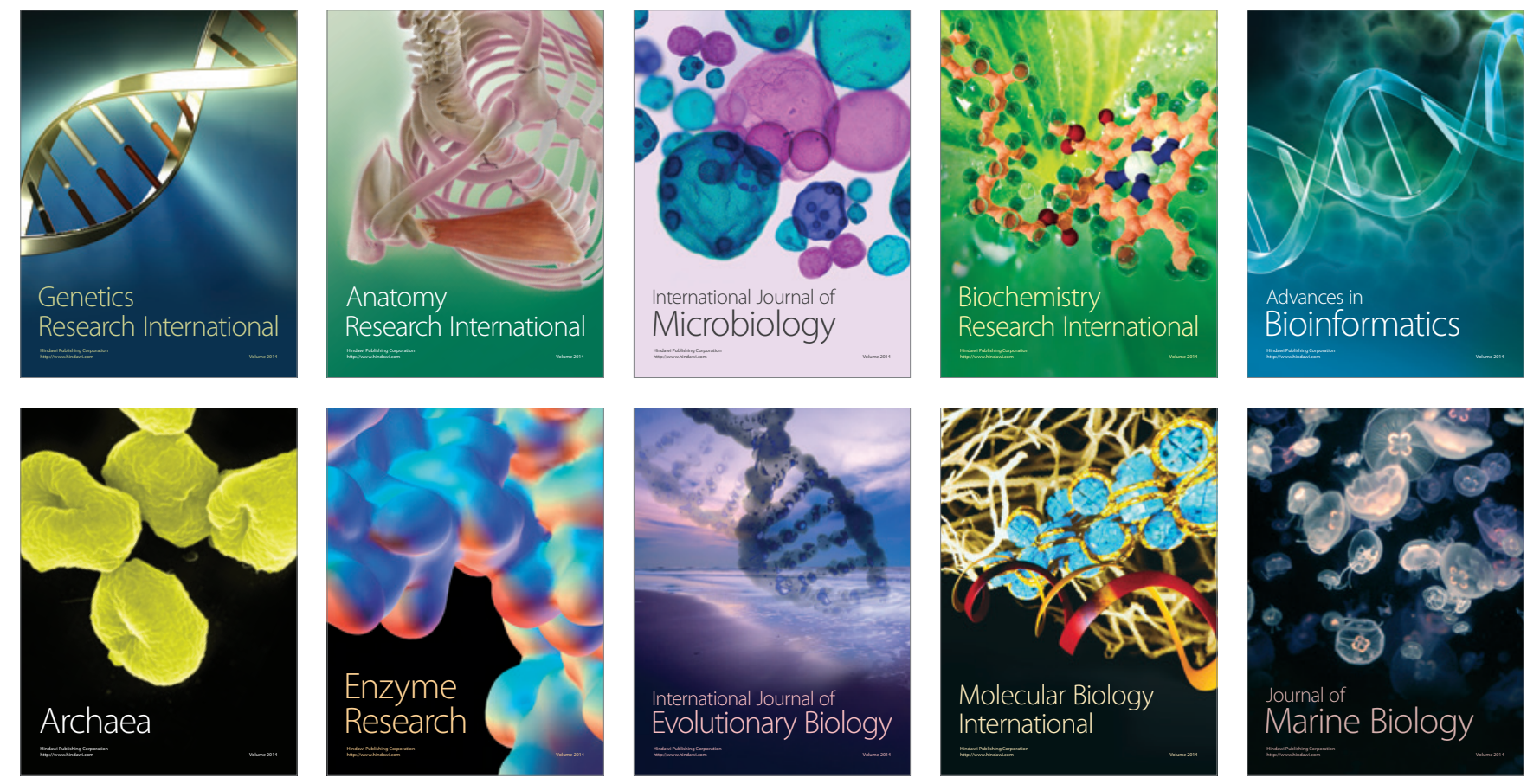